\title{
Embedding Guides Where Students Learn: Do Design Choices and Librarian Behavior Make a Difference?
}

Accepted Manuscript

Published in Journal of Academic Librarianship, vol. 39, issue 6, doi:10.1016/j.acalib.2013.06.007

Author Contact Information:

Sarah Anne Murphy, MLS, Professor, The Ohio State University Libraries, murphy.465@osu.edu

Elizabeth L. Black, MLIS, Associate Professor, The Ohio State University Libraries, black.367@osu.edu

Citation:

Murphy, S.A.; Black, E.L. (2013). Embedding Guides Where Students Learn: Do Design Choices and Librarian Behavior Make a Difference? JOURNAL OF ACADEMIC LIBRARIANSHIP, 39 (6), 528-534. doi:10.1016/j.acalib.2013.06.007 


\begin{abstract}
This study investigated whether library guides embedded in a university's learning management system fulfill their mission to promote library resources and maintain a librarian presence in the online course environment. Specifically, the study examined whether design elements, promotional practices, or other behaviors influenced guide use. It questioned whether students located the library guides and, if so, did students find the guides helpful. Results confirmed that students who used library guides found the guides helpful. Select faculty and librarian behaviors may also influence student use of library guides. Promotion and marketing practices, however, are not the only factors encouraging students to use library guides.
\end{abstract}




\section{Introduction}

As academic librarians work to embed themselves into their university's learning management system (LMS) to promote library resources and maintain a librarian presence in the online course environment, strategies for maximizing success are required. Recent discussions on learning analytics reveal the potential of capturing data collected by learning management systems (LMS) to inform course development and improve instruction. (" $1{ }^{\text {st }}$ International Conference on Learning Analytics and Knowledge," 2011) Data-mining in particular can provide valuable information regarding student use of certain online learning tools in relation to the costs incurred for creating or maintaining these tools. (Baepler \& Murdoch, 2010; Cohen \& Nachmias, 2011; Griffiths \& Graham, 2009; U. S. Dept. of Education, 2012) While usage data for library guides serve as a valuable surrogate for the impact of these pages, data alone fails to illuminate why students use some library guides more than others. This study examined whether design elements of library guides facilitate the use of library guides and whether faculty and librarian behavior influence guide use. As guides may be embedded either passively or actively in a course, such research is necessary to confirm whether library guides are successfully fulfilling their mission to promote library resources and maintain a librarian presence in the online course environment.

\section{Research Questions}

This study examined library guides embedded in Carmen, the learning management system (LMS) operating on the Desire2Learn (D2L) platform at The Ohio State University. Research questions included:

1. Are students finding library guides embedded in Carmen, and if so, do they find them helpful? 
2. Do library guides with high use in relation to class enrollment differ in design elements and composition when compared to guides with low use in relation to class enrollment? Are simplified library guides, with fewer widgets and more links more effective than library guides with more in-depth coverage?

3. Are pages with high use in relation to class enrollment assigned at the course level more frequently than pages with lower levels of use?

4. What actions did librarians take to promote library guides with high use in relation to class enrollment?

The authors theorized that a simplified library guide, with fewer widgets and links might be more effective than a library guide with more in-depth coverage. They also wondered whether assigning a guide at the course level truly influences page use. By exploring the factors which positively impact library guide use, the authors hoped to identify best practices for reaching students via library guides embedded in the LMS, regardless of whether a librarian was actively engaged with a course, instructor or students. Further, by investigating the use of the library guides by number of visits and by helpfulness to students a broader picture of the value of library guides is possible.

\section{Literature Review}

Library guides embedded within a university's learning management system (LMS) is a relatively new phenomenon. Much was written during the early development of campus courseware systems expressing the need for librarians to have a presence in such systems. (Bell \& Shank, 2004; Cohen 2002; Flecker \& McLean, 2004; Gibbons, 2002) Recent case studies have focused on how a library created their own system, or implemented a tool such as LibGuides to accomplish this objective. (Adebonojo, 2010; Casden, Duckett, Sierra, \& Ryan, 2009; Collard \& 
Tempelman-Kluit, 2006; Gonzalez \& Westbrock, 2010; Reeb \& Gibbons, 2004; York \& Vance, 2009) Sharing of detailed data regarding overall use of these pages, however, is limited, and descriptive in nature. The most heavily used library guide, for instance, is usually mentioned in a case write-up, but no detailed analysis of why other pages are used less frequently is provided. Further information regarding best practices for developing these pages has mainly focused on the overall project implementation, not the implementation of individual elements within the pages themselves. (Adebonojo, 2010; Gonzalez \& Westbrock, 2010)

While products such as LibGuides permit standardization through templates, such systems allow much flexibility for configuring page styles within each guide, reflecting " the different personalities of instructors" or librarians, rather than providing patrons with a truly unified product. (Brooks-Tatum, 2012) Most libraries and librarians recognize that pages created to support specific course assignments tend to receive the most use, supporting Reeb and Gibbons' observation that students' approach to research is less disciplined focused, and more geared towards completing the immediate task at hand. (Reeb \& Gibbons, 2004)

Empirical studies examining the use of library content delivered in the LMS have only recently been published. In 2012 studies, for instance, two separate research teams surveyed users and/or non-users of library guides. (Bowen, 2012; Leeder, Lonn, \& Hollar, 2012) In both studies, however, the guides themselves were only delivered to sub-sets of the university. The study reported in this article is unique in that it explores usage of guides delivered to all courses within a university's LMS.

\section{Carmen Library Link: A Unique Approach}


The Ohio State University (OSU) Libraries introduced Carmen Library Link (CLL) in 2007 to establish a librarian presence in each course in the university's learning management system (LMS). (Black, 2008; Black \& Blankenship, 2010) The CLL system is unlike library tools implemented at other institutions in that it consists of both permissions-based and nonpermissions based components. OSU librarians, for example, do not need the permission of an instructor to embed a library guide within a course. This means that each of the 5,375 course pages in the CLL system during the 2010 to 2011 academic year had one of 178 library guides assigned. While guides are uniform in appearance, with a librarian and a home library assigned, librarians customize some guides in concert with faculty to target the specific needs of students enrolled in individual courses. Other guides are passively pushed to an entire department or college, embedding a library presence with sometimes unanticipated results.

Ohio State faculty have a second, permissions-based option to allow OSU librarians to fully participate in a course. By assigning the librarian role within a Carmen course, faculty give librarians broad rights to view and insert content into the course, participate in online class discussions, obtain student feedback, and develop pages within the course LMS space.

OSU librarians develop library guides in the CLL system to highlight targeted library materials or services of use for a particular course or typically used by a department or college. The system consists of three main elements: links, widgets, and pages or guides. (Figure 1) Links are the smallest elements of each page, consisting of an html link to a specific resource and a description of the resource, written by the librarian who created the link. Links are encoded to facilitate student access to subscription databases off-campus and are pulled together in widgets, or a collection of related links. Widgets are then assembled to create the library guide.

Librarians last connect a guide to a specific course, to an academic department or to an academic 
college. Guides can be connected to multiple entities, thus, for example, a single guide could be connected to several courses as well an academic department.

When students click on 'Library,' which appears in the Carmen menu for each course, they receive the most specific library guide available. (Figure 1) The system looks first for a course-specific connection to a guide, then for an academic department level connection, and last a college level connection. If a connection to a guide is not found at any of those levels, a default University Libraries resource page will appear. Thus, every course in the Carmen system has a CLL library guide assigned.

The CLL system is similar to the widely-used LibGuides product in that it allows re-use of items and collections of items across different guides. The two systems differ, however, in the delivery of the guides. In the CLL system, the link to the page resides in the LMS and clicking the link initiates logic to deliver the most specific guide assigned for that course. Thus pages are delivered at a course level for students even when the guide was built at an academic department or college level by the librarian. Librarians can change the level of delivery as they wish and the system responds immediately. LibGuides only permits the creation of the guides. This system is not linked in any way to a campus' LMS.

\section{Methods}

Reasoning that usage data alone could not adequately address the research questions listed above, the authors used a mixed methods approach, collecting and analyzing data using both quantitative and qualitative techniques. To address the research questions, the study consisted of four parts. 
Part one explored whether students are finding library guides in Carmen, and if so, do they find them helpful? The authors analyzed data collected in concert with a 2011 Project Information Literacy (PIL) study at Ohio State. The OSU-only segment of the PIL study asked 100 OSU undergraduate students to look at a screenshot of a Carmen course page and indicate what they noticed first and second on that page. The interviewer then asked the students if they noticed the link to the "library guide on the page. Students were then shown a screen shot of a sample library guide and asked if they had used a library guide during spring quarter 2011, the quarter which coincided with the study. Those who indicated they used a library guide then answered two follow-up questions. The first asked students to select one or more reasons for their last use of the guide from a list of six. This list included a category labeled 'other.' The second question asked students to indicate ways the guide was helpful by selecting one or more answers from a list of ten. This list also included an 'other' category. Both lists were based on items noted to be important to students in Head and Eisenberg's 2010 Project Information Literacy study, Truth Be Told: How College Students Evaluate and Use Information in the Digital Age. (Head \& Eisenberg, 2010)

Part two of the study explored use of library guides. To identify and compare library guides with high use in relation to class enrollment to guides with low use, all transactions on the CLL system from July 1, 2010 through June 30, 2011 were analyzed. The data included usage information for each library guide, as well as the name and number of the course to which the library guide was assigned, the library guide name and ID, the email address for the librarian responsible for maintaining the guide, and whether the guide was assigned at the course, department, or college level. No personal identifying information, such as a student's name, IP address, or college was collected. 
Since large enrollment classes could theoretically generate higher usage, the number of students enrolled in each course was then matched to the library guide usage data. The authors calculated a ratio reflecting the average number of times one individual enrolled in a particular course offering accessed the library guide by dividing the total number of times a library guide was accessed by that course's enrollment. For the purposes of this study the authors defined high use as a ratio of at least two visits per student enrolled in a course. The ratios for all guides was sorted from the highest to lowest, revealing that in 192 (4\%) of the 5,375 Carmen courses with library guides assigned during the 2010-2011 academic year, the average student used the assigned guide at least twice. In all, 44 (25\%) of the 178 guides maintained by librarians received high use in at least one course.

The third part of this study examined whether library guides with high use in relation to class enrollment differ in design elements and composition when compared to guides with low use. To so investigate this question, a screenshot of all current library guides was taken over a two day period in September 2011. Librarians can change their guides at any time, thus taking screenshots ensured the stability of the guides being studied. A coding matrix using a simple Excel spreadsheet guided the qualitative content analysis of each page. This matrix captured general information such as the total number of widgets on each page, the total number of links assigned to each widget, the url and title for each link on the page, the page title, and the number of the widget to which the link was assigned.

The authors also examined the composition of the widgets and characteristics of the items themselves. At the widget level, the authors noted whether the librarian included welcoming or instructional text at the beginning of a widget. For each link, they recorded whether descriptive text was provided and classified the content of each link, using broad categories. 
The fourth and final part of the study involved interviewing individual librarians who maintained at least one page that was used by the average student at least twice in a course to investigate whether faculty and librarian behavior influenced this high use of the library guides. The interview protocol asked the librarians to describe

- how they used library guides,

- whether their guides related to their engagement work, and

- how they decided at which level (course, department, or college) to assign a guide

During the interview, the librarians were shown a copy of up to three of their library guides which received high use. The interviewer asked the librarians to talk about the guides and the courses in which their library guide was used at least twice per enrolled student in general. Next librarians were asked to describe any actions they engaged in to promote the guide to students in these specific courses, and to identify any other factors they thought might have influenced the use of the guides for those particular courses

Since a library guide may be linked to more than one course, and librarians can create and maintain more than one guide, 14 of the 33 librarians who currently maintain library guides in Carmen were eligible to participate in the interview portion of this study. These librarians were recruited via a personal email from the study authors. One author conducted the interviews. Both authors performed the qualitative analysis of the interview transcripts using a simple Excel spreadsheet.

\section{Results}


During the OSU-only segment of the PIL interviews, students shown the screenshot of a basic Carmen course page primarily reported seeing the 'news' feature first, followed by the navigation bar on the lower left of the screen. When asked whether they noticed the link to the Library guide, 33 of the 100 students interviewed indicated the guide was familiar to them. Only 21 , however, reported they used the guide during spring quarter 2011, the quarter in which the interviews were conducted.

More freshmen used the guides during spring quarter than sophomores, juniors, or seniors. (Figure 2) The majority of guide users also reported having a B average or above. Most users indicated the guide helped them to find sources for a research assignment and to find a specific library on campus. (Figure 3) Guide users also shared multiple explanations of how the guides helped them, with the majority reporting the guides helped them to learn something new $(n=19)$. Students also noted that the guides helped them to get started on a research paper or assignment $(n=16)$, find research materials for their course $(n=15)$, and get their research paper or assignment done $(n=12)$. Additionally, users reported the guides helped them to comprehensively investigate a topic $(\mathrm{n}=11)$ and understand what libraries on campus had to offer $(n=8)$. Most students also believed the guide helped them to get a good grade $(n=14)$.

Initial analysis revealed that almost all library guides with high use in relation to class enrollment were assigned at the department and the college level. (Table 1) This challenged the prevailing notion that course-specific library guides receive the most use. (Reeb \& Gibbons, 2004) Surprisingly, more than $68 \%$ of low-use pages, for example, were actually assigned at the course level.

The average guide consisted of 5 widgets and a total of 20 items. (Table 2) Of the 531 widgets in the Carmen Library Link system, 53 were assigned to both high-use and low-use 
guides. While high-use guides had a slightly higher average number of widgets and links assigned than low-use guides, the average number of links assigned to high-use guides is actually lower than the average number of links assigned to any guide in the CLL system. In all, 1,343 links were assigned 778 times to high-use pages and 1,774 times to low-use pages. This suggests that a simplified library guide with fewer widgets and links may be more effective than a guide which provides more in-depth coverage, but the difference was small enough that this conclusion requires further research.

Few differences were identified in the design elements and composition of high-use guides in comparison to low-use guides. Both provided descriptive text explaining the content of the link, its context for the page or the course, or why the link might be useful to a student. (Table 2). All guides included at least one or more widgets with links promoting the OSU library catalog, the OhioLINK catalog, the Ohio State University Libraries library.osu.edu homepage, or WorldCat Local. (Table 3) This suggests that future designs of the guide template should automatically include links to these resources.

High-use and low-use guides also promoted the OSU Libraries Research Databases List, the Libraries A-Z Online Journal List, tutorials, and services such as the libraries' Article Express document delivery program with nearly the same frequency. Closer examination of links to OSU library catalog records also revealed few differences. Both high-use and low-use guides promoted major databases or full-text resources. On the 178 library guides maintained in the CLL system, the most popular catalog record links included: Academic Search Complete (55), JSTOR (38), MLA International Bibliography (20), BIOSIS Previews (16), and PubMed (13). Of the 44 library guides with high use in relation to course enrollment, 24 (55\%) pages were assigned at the course level, $13(30 \%)$ at the department level, and $6(14 \%)$ at the college 
level. (Table 1) Information about the use of the guides in 77 Carmen courses was collected. This represented only $40 \%$ of the 192 Carmen courses in which the guide was used at least twice per student enrolled since guides can be assigned to multiple courses and librarians interviewed were only asked to comment on up to three of their high-use guides. While half of the librarians interviewed sought to create and connect course-specific guides whenever possible, several indicated they initially created department level guides, and as they had an opportunity or need, created course level guides for a specific faculty member or course. One noted her strategy was to create "general discipline [guides] at the department level," focusing on basic tools and RefWorks. She then works to create course level pages "where she sees students struggling." Some librarians have focused on creating departmental or college guides overall "so I can reach as many students as possible and so I can reach subject areas where I don't teach.”

Interviews revealed that more than half of the librarians with at least one high-use guide had the opportunity to either use or promote their guide during a library instruction session. Five of the 14 librarians interviewed generally used their guides to highlight major sources, while another five created their high-use guides to support specific assignments. One librarian offered to create a course-specific guide for students "anytime I'm asked to visit a class." Most found library guides "an easy way to reach a lot of students without being there."

Actions librarians with at least one high use guide took which may have impacted guide included announcing the page to faculty or students in a forum outside of a class session for $47 \%$ of the 77 courses with high-use guides, or physically visiting a class session for $48 \%$ of the courses. For $39 \%$ of the 77 courses with high-use guides, the librarians interviewed were assigned the 'librarian' role in the LMS course site, giving them permission to more fully participate in the development and delivery of the course. (Table 4) 
Surprisingly, for $31 \%$ of the 77 courses with high-use guides, the librarians interviewed could not identify any actions they took which may have impacted usage. All of these guides were assigned at the department or college level, indicating the librarian did not have direct involvement with the course. Still, these guides were fulfilling their mission to maintain a librarian presence in the online course environment. Most of the librarians interviewed credited the content of the guide itself as influencing its use. For $48 \%$ of the 77 courses with high-use guides assigned to them librarians indicated that the content of the page was appropriate to meet the needs of students. Librarians also noted that for $42 \%$ of the 77 courses their library guide supported a major research or writing assignment. Faculty encouraged use of the library guide in $31 \%$ of the 77 courses with high-use guides.

\section{Discussion}

This study confirmed that students find library guides delivered through the LMS helpful and that several factors impact the discovery and use of these pages. While customization of guides for specific assignments and direct librarian involvement with courses has a positive influence on guide use, these factors alone do not explain student use of library guides embedded into the LMS. A significant number of the high-use pages had no librarian involvement in the course at all.

Most students who participated in the OSU-only segment of the PIL interviews did not find the library guide on their own. Those who did, however, identified multiple ways the guide was helpful to them. Of the 100 students interviewed in spring 2011, almost a third (33) of the students were familiar with the library guides, but only 21 indicated using a library guide that quarter. Of particular interest, 16 of these 21 students reported that a library guide helped them to get started on their research paper or assignment. Another 15 reported a guide helped them to 
find research materials for their coursework. Head and Eisenberg indicated that for all steps in the research process, these are two areas in which students struggle the most. (Head \& Eisenberg, 2010) Bowen's study also confirmed that students who used a library guide accessed from within the LMS found the guide useful for finding resources. (Bowen, 2012) This demonstrates that embedding library guides in the LMS is an effective way to assist students with information tasks that research shows are most challenging to them.

Freshmen and sophomores interviewed were more likely to be familiar with the library guide than juniors and seniors. The authors hypothesize that this might be a result of the recent use of library guides by librarians working closely with high-enrollment, lower-level courses, including the first year writing course. As students become familiar with the library guide in Carmen, it is hoped that they will take this knowledge with them to other courses. Since Ohio State added library guides to all courses in the LMS for the first time in 2009, upper class students interviewed were not exposed to library guides delivered through the LMS early in their academic experience. Further research is required to test the hypothesis that students transfer knowledge of the library guide in Carmen to future courses.

If students who use the guides find the guides helpful, how might librarians better facilitate student's ability to locate the guides? When shown the LMS course page, most students did not notice the link to the library guide initially. Instead the majority of the students interviewed first noticed the news section and second noticed the lower navigation list on the course page. The lower navigation list is heavily used and modified by instructors. Thus placement of the 'Library' link in this location is not an option. This leaves the news section. Some of the librarians interviewed obtained the librarian role from the instructor of the course to which their guide was assigned. This role gave them permission to edit several areas of the 
course website in the LMS, including the news section. Some of the librarians who had high-use pages reported using the news section to feature resources and the library guide. Thus, promotion of a guide and library resources directly within the LMS course shell is one potential best practice to be encouraged.

Few best practices could be inferred from the content analysis portion of the study. The authors expected that high-use guides would include widgets with instructive introductory text,. This was not the case. In a related finding, more low-use pages included descriptive text for each link. The minimal difference in composition and characteristics of high-use and low-use guides suggests that OSU librarians are constructing guides relatively uniformly, with some exceptions. Most limit the number of links on their guides, and focus on promoting specific electronic and print resources via links to the OSU Libraries catalog. High-use guides had slightly more widgets, or groupings of links, yet fewer links than the overall average number of links assigned to any guide in the system. This suggests that simpler groupings of items might be easier for students to use. However, the small difference makes this assertion uncertain and requires additional study.

While seven of the ten guides with the highest use in relation to course enrollment were assigned at the course level, close to $75 \%$ of low-use guides were also assigned at the course level. Further, it is interesting that nearly half of all high-use guides were assigned at the department or college level, and that guide authors had no insight into what might be driving use for at least one third of the courses to which these guides were assigned. For these guides, the strategy to passively embed a library presence into the Carmen course is working. Some academic disciplines, especially in the sciences, rely on a limited set of discovery tools, making the need for a customized library guide less pronounced. The strategy to start with a 
departmental guide, and then develop a course-level guide on request appears rational, but for select disciplines, may not be necessary or a valuable use of a librarian's time. This study suggests that placing a discipline-specific guide in the LMS can be as effective at reaching students as creating course-specific guides.

Librarian interviewees indicated that high-use guides were often linked to a course with a major research or writing assignment and had content focused on the needs of the students enrolled in the course. It is easy to assume that low-use course-level pages were also constructed with the needs of the students enrolled in a specific course in mind, and that many of these courses also included major research or writing assignments. Since this study focused on highuse pages and the actions of librarians related to those pages, only librarians who authored highuse pages were interviewed. Follow-up interviews with librarian authors of low-use guides and analysis of the course assignments themselves are needed to confirm if major research or writing assignments truly drive page use.

Still, librarian engagement with students and faculty may serve as a best practice influencing guide use. Librarians with high-use guides indicated that they engaged in some action related to close to half of the courses in which the guide was used twice per student enrolled.

While additional interviews with librarian authors of low-use guides may also me needed to confirm that engagement activities influence guide use, it is significant that nearly half of all high-use guides were surprises to their librarian authors because the librarian had not worked specifically with the instructors or students involved in the course. This demonstrates that one of the strengths of passively embedding a library guide into each course in the LMS is that library content may be delivered where students need it without intervention by either librarian or 
instructor. Since completion of this study in fall of 2012, the authors have discovered a $257 \%$ increase in usage of library guides embedded in Carmen since the 2009-2010 academic year. Formal promotion of library guides may not be necessary, especially if the availability of guides is emphasized early during an undergraduate student's academic career. For example, since the 2010-2011 academic year, graduate student instructors of all sections of English 1100 have been encouraged to use the library guides to teach information literacy concepts directly to undergraduate students. Students enrolled in introductory level Chemistry courses are also using the guides to directly access sources such as the CRC Handbook of Chemistry and Physics. (Black, 2013)

\section{Conclusion}

This study demonstrates that librarians who advocated for library representation in learning management systems correctly recognized a significant opportunity. Students who use library guides delivered through a LMS find the guides useful. Several factors encourage and support student discovery of library guides in the LMS, including direct librarian involvement with the course, either in the LMS or physically. However, direct librarian involvement with the course is not required to reach students and have a positive outcome on their learning. Nearly half of high-use guides were surprises to their librarian authors, revealing engagement activities were just one of many factors influencing guide use. Promotion of library guides during key introductory level course-work instead, may more strongly influence student use of library guides embedded in the LMS during their academic career. Future research is required to explore student use of library guides embedded within the LMS throughout their academic career. 


\section{Acknowledgement}

The authors are grateful to colleagues at Project Information Literacy who granted us permission to use and modify their survey question (\# 11), which was used in their 2010 "Truth Be Told" survey. The survey was administered to 112,844 students on 25 U.S. campuses between April 6, 2010 and May 18, 2010. 


\section{References}

1st International Conference on Learning Analytics and Knowledge 2011 | Connecting the Technical, Pedagogical, and Social Dimensions of Learning Analytics. (2012). Retrieved from https://tekri.athabascau.ca/analytics/

Adebonojo, L. G., (2010). LibGuides: Customizing Subject Guides for Individual Courses. College \& Undergraduate Libraries, 17(4), 398-412.

Baepler, P. \& Murdoch, C. J. (2010). Academic Analytics and Data Mining in Higher Education. International Journal for the Scholarship of Teaching and Learning, 4(2), 1-9.

Bell, S. J. \& Shank, J. D. (2004). Linking the Library to Courseware: A Strategic Alliance to Improve Learning Outcomes. Library Issues, 25(2), 1-4.

Black, E. L. (2008). Toolkit Approach to Integrating Library Resources into the Learning Management System. Journal of Academic Librarianship, 34(6), 496-501.

Black, E. L. \& Blankenship, B. (2010). Linking Students to Library Resources through the Learning Management System. Journal of Library Administration, 50(5/6), 458-467.

Black, E.L. (2013, Feb. 28). Carmen Library Link Use Increases. [Blog post]. Retrieved from http://digitalunion.osu.edu/2013/02/28/carmen-library-link-use-increases/ 
Bowen, A. (2012). A LibGuides Presence in a Blackboard Environment," Reference Services Review 40(3), 449-468.

Brooks-Tatum, S. (2012). Delaware State University Guides Patrons into More Effective Research with Standardized LibGuides. Against the Grain, 24(1), 16-18.

Casden, J., Duckett, K., Sierra, T., \& Ryan, J. (2009). Course Views: A Scalable Approach to Providing Course-Based Access to Library Resources. Code4lib Journal, (6). http://journal.code4lib.org/articles/1218

Collard, S. \& Tempelman-Kluit, N. (2006). The Other Way In: Goal-based Library Content through CMS. Internet Reference Services Quarterly, 11(4), 55-68.

Cohen, A. \& Nachmias, R. (2011). What Can Instructors and Policy Makers Learn About Websupported Learning through Web-usage Mining. The Internet and Higher Education, $14(2), 67-76$.

Cohen, D. (2002) Course-Management Software: Where's the Library? Educause Review, 37(3), $12-13$

Flecker, D. \& McLean, N. (2004). Digital Library Content and Course Management Systems: Issues of Interoperability. Washington, D.C.: Digital Library Federation. 
Gibbons, S. (2002). Defining the Challenge. Library Technology Reports, 41(3), 4-6.

Gonzalez, A. and Westbrock, T. (2010). Reaching Out with LibGuides: Establishing a Working Set of Best Practices. Journal of Library Administration, 50(5), 638-656.

Griffiths, M. E. \& Graham, C. R. (2009). Patterns of User Activity in the Different Features of the Blackboard CMS across All Courses for an Academic Year at Brigham Young University. MERLOT Journal of Online Learning and Teaching, 5(2), 285-292.

Head, A. J. \& Eisenberg, M. B. (2010). Truth Be Told: How College Students Evaluate and Use Information in the Digital Age. Project Information Literacy Progress Report. Retrieved from http://projectinfolit.org/pdfs/PIL Fall2010 Survey FullReport1.pdf

Leeder, C., Lonn, S., \& Hollar, S. (2012). Use of Library Tools in a Learning Management System. In ACM International Conference Proceeding Series (595-597).

Reeb, B. \& Gibbons, S. (2004). Students, Librarians, and Subject Guides: Improving a Poor Rate of Return. Portal: Libraries and the Academy, 4(1), 123-130.

U.S. Dept. of Education. (2012). Research \& Reports. Retrieved from http://www.ed.gov/edblogs/technology/research/ 
York, A. \& Vance, J. (2009). Taking Library Instruction into the Online Classroom: Best Practices for Embedded Librarians. Journal of Library Administration, 49(1), 197-209. 
Figure 1. Screenshot of Sample Library Resource Page Embedded in a Carmen Course

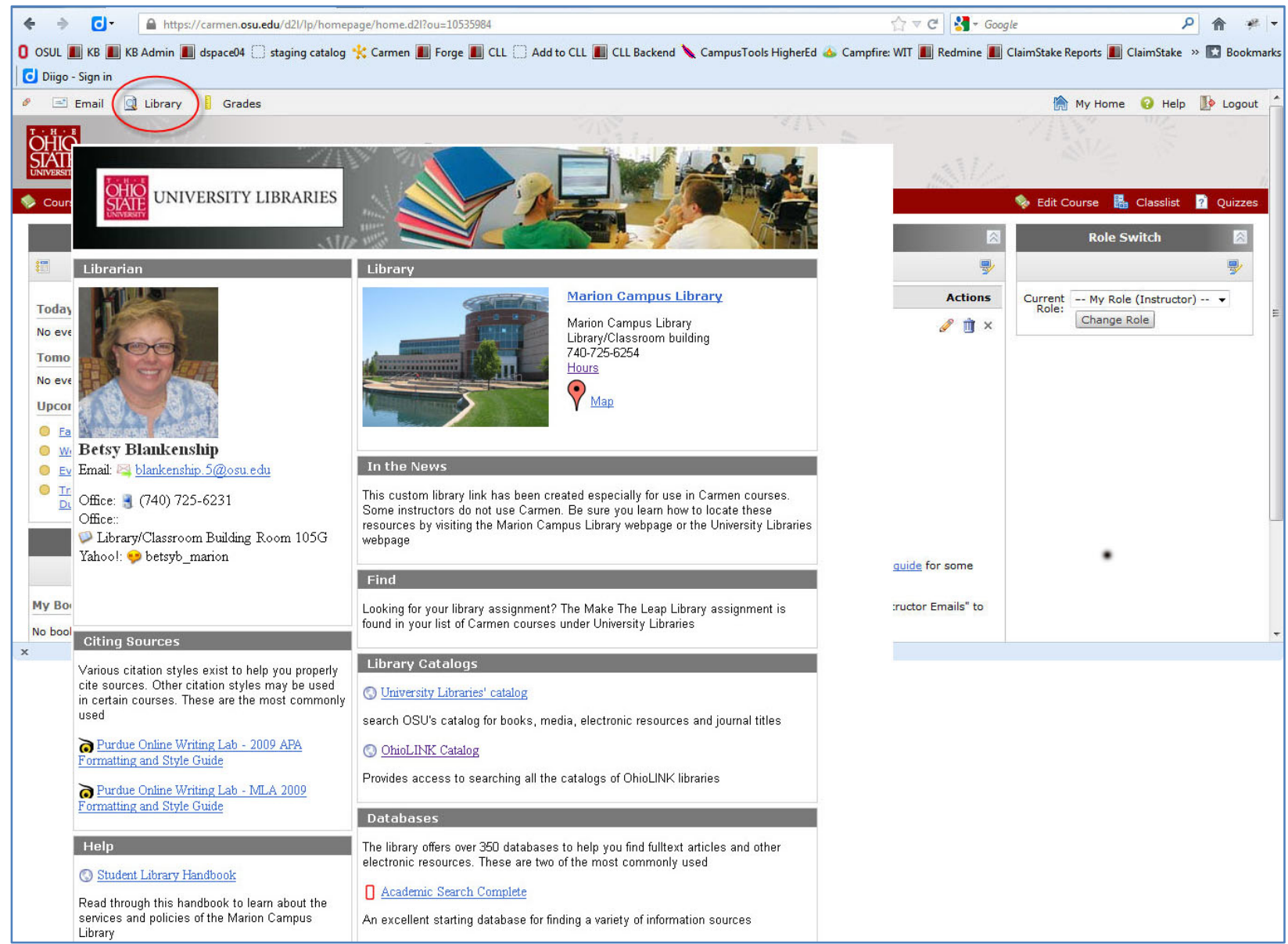


Figure 2. Dashboard Profile of Undergraduates Who Reported Using a Library Guide During Spring Quarter 2011

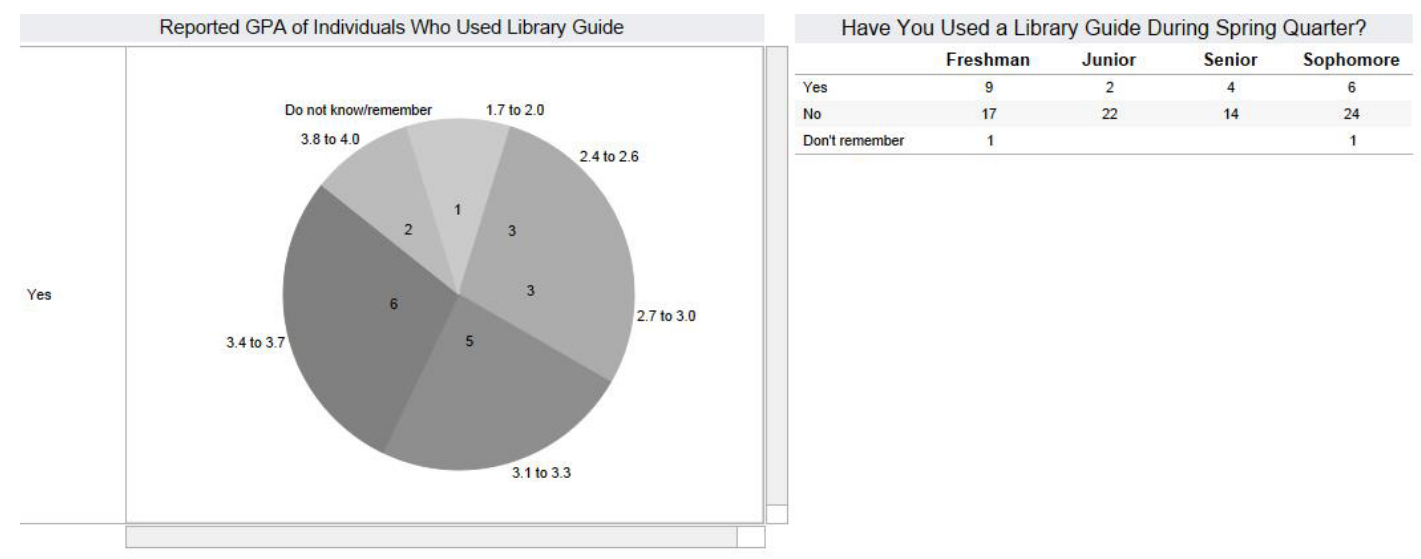


Figure 3. Dashboard Presenting Students' Reasons for Using a Library Guide and Indications of Guide Helpfulness

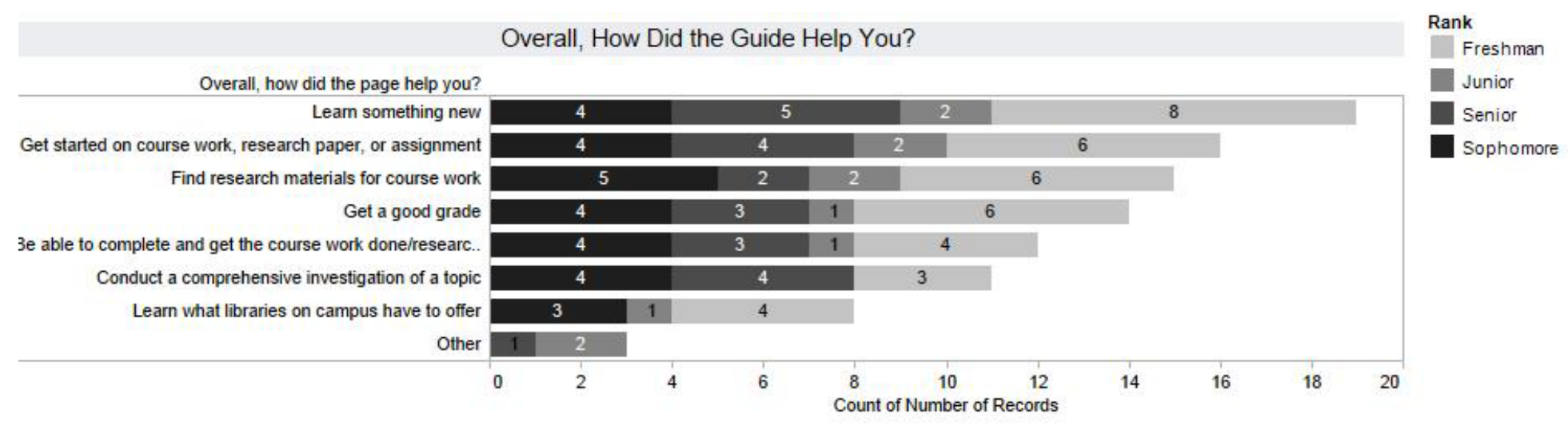

Why Did You USe the Library Guide, By GPA and Rank

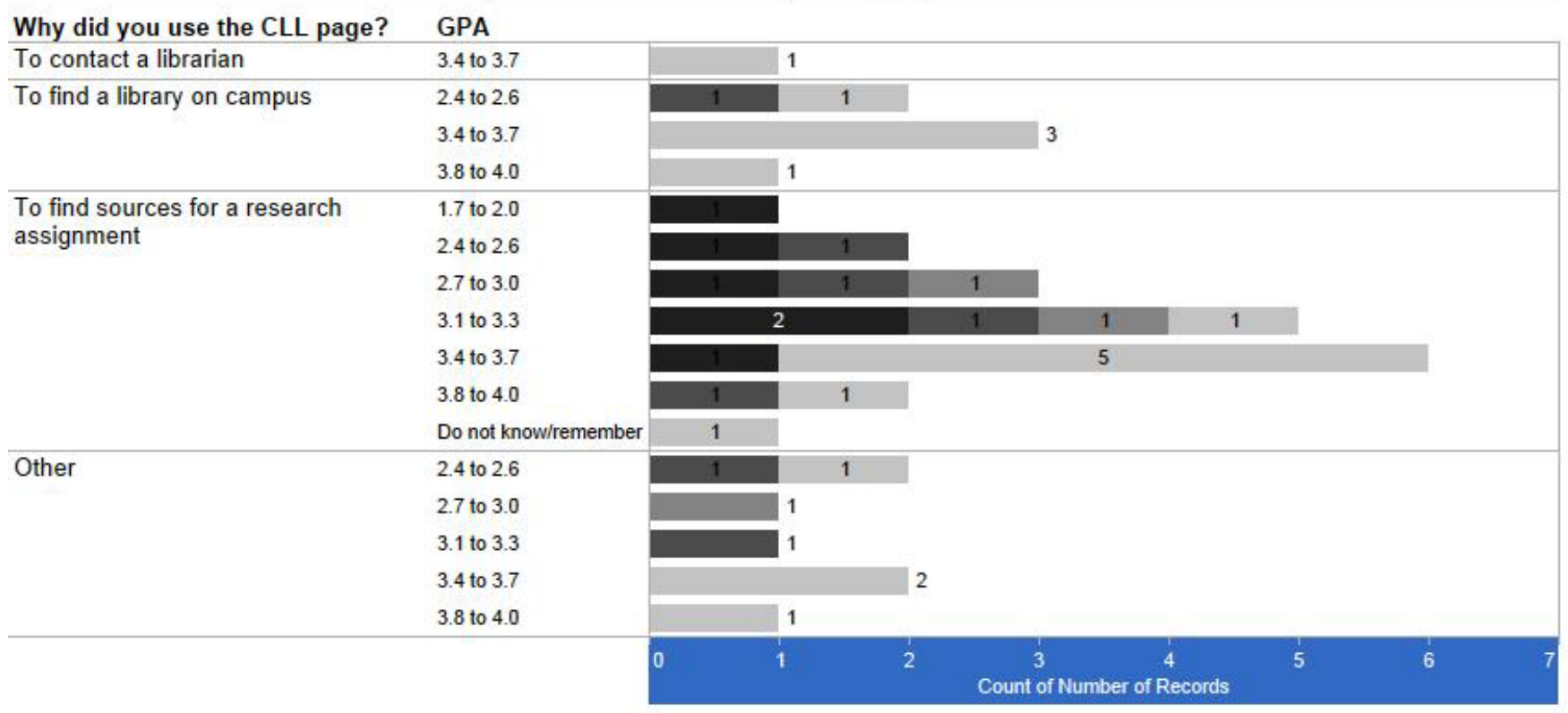


Table 1. Library Guide Assignment by College, Department, or Course Level

\begin{tabular}{lcc}
\hline Assignment Level & $\begin{array}{c}\text { Overall Number Assigned } \\
\mathrm{n}\end{array}$ & $\begin{array}{c}\text { Number Assigned to High } \\
\text { Use Pages } \\
\mathrm{n}, \%\end{array}$ \\
\hline College & 6 & 6 \\
Course & 132 & 25 \\
Department & 54 & 13 \\
Total & 192 & 44
\end{tabular}


Table 2. Overview of Widget Composition and Link Characteristics

\begin{tabular}{lccc}
\hline & High-Use Page & Low-Use Page & Total \\
\hline $\begin{array}{l}\text { Total number of links assigned to CLL pages* } \\
\text { Total number of widgets assigned to all CLL }\end{array}$ & 778 & 1774 & 2552 \\
pages & 230 & 619 & 849 \\
Average number of links on CLL pages & 23 & 19 & 20 \\
$\begin{array}{l}\text { Average number of widgets on CLL pages } \\
\text { Number of widgets used exclusively on one }\end{array}$ & 5 & 5 & 5 \\
CLL page & 122 & -- & 135 \\
$\begin{array}{l}\text { Number of widgets assigned to both high and } \\
\text { low use pages }\end{array}$ & -- & 57 \\
$\begin{array}{l}\text { Number of widgets with introductory or header } \\
\text { text provided }\end{array}$ & 35 & 1511 & 2137 \\
$\begin{array}{l}\text { Number of links on page with descriptive text } \\
\text { provided to explain the content of a link, its } \\
\text { context, or why it might be useful to a student }\end{array}$ & 626 & \\
*There were 1,343 unique links in the Carmen Library Link System. A link may be assigned to \\
more than one CLL widget.
\end{tabular}


Table 3. Percentage of Links By Category on High-Use Library Guides in Comparison to Percentage of Links on Low-Use Library Guides

\begin{tabular}{lcc}
\hline Category & $\begin{array}{l}\text { High-Use } \\
\text { Page }\end{array}$ & $\begin{array}{l}\text { Low-Use } \\
\text { Page }\end{array}$ \\
\hline $\begin{array}{l}\text { Link promotes the OSU Libraries website } \\
\text { (http://library.osu.edu), the OSU Library Catalog, the }\end{array}$ & 6.18 & 5.25 \\
\hline $\begin{array}{l}\text { OhioLINK Library Catalog, or WorldCat Local } \\
\text { Link promotes the OSU Libraries Research Databases List } \\
\text { or A-Z Online Journal List }\end{array}$ & 3.60 & 3.33 \\
$\begin{array}{l}\text { Link provides a permanent URL to an OSU Libraries } \\
\text { Catalog Record }\end{array}$ & 40.67 & 43.15 \\
$\begin{array}{l}\text { Link promotes an OSU Libraries services, such as Article } \\
\text { Express }\end{array}$ & 10.94 & 3.46 \\
$\begin{array}{l}\text { Link connects to a tutorial } \\
\text { Link connects to a regional campus library website or } \\
\text { another OSU academic or administrative department. }\end{array}$ & 4.89 & 3.84 \\
$\begin{array}{l}\text { Link is to an external website not covered by a category } \\
\text { above. }\end{array}$ & 2.32 & 2.93
\end{tabular}


Table 4. Percentage of Actions or Factors Impacting Usage of Pages Embedded in 77 Carmen Courses, By Course

\begin{tabular}{lc}
\hline Action & Percentage \\
\hline Assigned 'librarian' role in course & 38.96 \\
$\begin{array}{l}\text { Content of page appropriate for needs of students enrolled in } \\
\text { course }\end{array}$ & 48.05 \\
Course has major research or writing assignment & 41.56 \\
No action identified & 31.17 \\
Page availability announced to students in general orientation & 46.75 \\
or faculty via a departmental email list or during a faculty & \\
meeting & \\
Use of page encouraged by instructor & 31.17 \\
Visited class & 48.05 \\
Other & 24.67
\end{tabular}


